\title{
Working Memory in Writing: Empirical Evidence From the Dual-Task Technique ${ }^{1}$
}

\author{
Thierry Olive \\ CNRS \& University of Poitiers, France
}

\begin{abstract}
The dual-task paradigm recently played a major role in understanding the role of working memory in writing. By reviewing recent findings in this field of research, this article highlights how the use of the dual-task technique allowed studying processing and shortterm storage functions of working memory involved in writing. With respect to processing functions of working memory (namely, attentional and executive functions), studies investigated resources allocation, step-by-step management and coordination of the writing processes. With respect to short-term storage in working memory, experiments mainly attempted to test Kellogg's (1996) proposals on the relationship between the writing processes and the slave systems of working memory. It is concluded that the dual-task technique revealed fruitful in understanding the relationship between writing and working memory because researchers exploited its major advantage, namely its flexibility.
\end{abstract}

Key words: Writing, working memory, dual-task, phonological loop, visuospatial sketchpad, central executive, processing demands, dynamic of writing

Writing is one of the most complex cognitive activities that Human Beings accomplish during their life. Writing indeed involves a large number of cognitive components that operate at different levels of representation. For instance, at a semantic level, planning processes construct a pre-verbal message that corresponds to the ideas a writer wants to communicate. In this stage, ideas are retrieved from long-term memory and (re-)organized if necessary. Planning processes also allow scheduling the unfolding of writing by preparing action plans for composing (Hayes \& Grawdol-Nash, 1996). A second set of processes, the translating processes, involves a linguistic level of representation in which the pre-verbal message resulting from the planning processes is transformed into a verbal message. The conceptual structure elaborated during planning is thus grammatically encoded by retrieving in the mental lexicon the syntactic and morphological properties of words (Bock \& Levelt, 1994). A third component allows comparing the text already written to the writer's mental representation of its own intended text by launching procedures aiming at improving the text, both at the conceptual and linguistic levels. A last component intervenes at a motor level of representation (Kellogg, 1996). Execution, or graphic transcription processes allow writers transforming the linguistic message into a sequence of motor programs for producing handwriting. Writing being thus a strongly integrative activity, understanding how writers compose a text does not only consists in descriptions of the processes underlying written production but also in explaining how their activation is orchestrated in the cognitive system, whose main characteristic is its limited capacity in simultaneously maintaining and processing information. In other words, one objective of writing research is to analyze the on-line management of working memory.

Psychologists have developed several techniques to analyze the management and cognitive demands of mental activities. For example, they use mental chronometry (Posner, 1978), visual search (Schneider \& Shiffrin, 1977), or event-related potentials (Humphrey \& Kramer, 1994). However, the most widely used is the dual-tasks technique. This is particularly true since working memory has been identified as playing a crucial role in complex cognitive activities. Numerous empirical evidences supporting the existence of working memory and its relationship with cognitive activities indeed came from dual-task experiments (Baddeley, 2000).

In this framework, the present review aims at showing that the dual-task technique largely contributed to the understanding of the relationship between writing and working memory. It begins by presenting the general principle of the dual-task technique and its potential limits. Then, the most influential models of working memory are described. The final section focuses on writing and working memory. It begins by describing models of writing that include working memory. Then, recent findings on the role of the phonological loop, the visuospatial sketchpad and the central executive during writing are summarized. This review focuses on the implication of working memory in writing at the light of only dual-task experiments. Consequently, other issues relevant to

\footnotetext{
1 This article does not exactly replicate the final version published in the journal "European Psychologist". It is not a copy of the original published article and is not suitable for citation. http://www.hhpub.com/journals/ep/
} 
working memory but not investigated with dual-tasks, such as individual differences investigated with correlational studies (for example, see Swanson \& Berninger, 1996) will not be examined.

\section{Dual Tasks}

Requiring participants to simultaneously perform two tasks (called on the one hand, the primary and, on the other hand, the secondary), this technique directly exploits the postulate that the cognitive system has a limited pool of cognitive resources (that must be defined before setting the secondary task). When simultaneously performed, the primary and secondary tasks share these cognitive resources. No longer having the amount of resources that they usually require, the primary or secondary tasks are affected and their performance is presumed to decrease. Consequently, comparing a dual-task condition with a single-task condition allows evaluating how resources are shared between the primary and secondary tasks.

Numerous secondary tasks have been designed. For example, in memory loads subjects have to memorize a set of items while performing the task under investigation (the primary task). In this case, it is postulated that the operations of the primary and secondary tasks engage information of similar nature and that they interfere. According to both the number of items memorized and the nature of the items, the secondary task has different impacts on the primary task. Probe tasks are another kind of secondary task. Signals (called probes) periodically appear during the experiment (Kerr, 1973) and participants are instructed to react as quickly as possible as they detect the probe. Dual-task performance at the secondary task is then compared with the performance in singletask condition. The latency of reaction to the probes assesses the amount of cognitive resources that is devoted to the primary task. Similarly, in tracking tasks, participants follow a target and the deviations from the target are interpreted as indicating resources consumption (for an example, see Power, 1986). In this two latter cases, it is postulated that the primary and secondary tasks draw on the same pool of central resources.

Although findings of dual-task experiments strongly contributed to a better comprehension of human cognition, many criticisms were raised against this technique. Some authors even claimed that the dual-task paradigm should no more be used. Howe and Rabinowitz (1989) for instance argued that the new interactions created for processing both the primary and the secondary tasks disabled any interpretation of performance in dual-task situation. Without going so far, the dual-task technique implies that researchers be particularly attentive on their implementation. One well-documented source of problem to be avoided relates to structural interference (Kahneman, 1973; Kerr, 1973). Namely, mechanisms engaged in perception of the secondary task or in its responses must be distinct from those engaged in the primary task. Regarding writing, responses of writers to secondary stimuli (e.g., probes) cannot involve the hand they use for handwriting.

By contrast, much more authors supported the use of the dual-task technique as long as some methodological precautions are respected when designing these experiments. For example, Fisk, Derrick, and Schneider (1986-87) proposed three criteria that may validate the interpretations of dual-task data when respected. According to the first criterion, the primary and secondary tasks must draw from a single pool of resources so that a trade-off between the two tasks can take place. The community of resources assumption can be tested by increasing the difficulty of the primary task. This should lead to decreases of performance at the secondary task. By contrast, if each task draws from a specific pool of resources, then - the secondary task should never be affected. The second criterion suggested by Fisk et al. (1987-88) concerns the intrusive character of the secondary task. When the primary task engages large amounts of resources, the addition of even a low-demanding secondary task might exceed the cognitive capacity and subjects are likely to carry out the secondary task with the detriment of the primary task. If so, data inform on the primary task only in this overloaded situation. This issue can be addressed by verifying whether or not performance at the primary task differs in single- or dual-task condition. The third criterion concerns the stability of resources devoted to the secondary task throughout the experiment. Indeed, changes in performance at the secondary task resulting from a change in its demands can be falsely allotted to changes in resources devoted to the primary task. In other words, no incidental learning must be observed at the secondary task. A simple test of this criterion consists in examining block effects in the experiment. In sum, when carefully designed, the dual-task technique allows psychologist to further answer very important question about the processing limits of the cognitive system and the role of working memory in cognition.

\section{Working Memory}

Working memory is aimed at explaining how information is temporary stored and processed during the realization of cognitive activities, and in particular in complex cognitive activities such as learning, language production and comprehension. One of the most influential model of working memory has been proposed by Baddeley and 
Hitch (1974) and then revised by Baddeley $(1986,2000)$.

This theoretical framework represents a development of earlier models of short-term storage (such as the model of Atkinson \& Shiffrin, 1968). According to Baddeley and Hitch (1974), working memory should be conceived as a multi-component system. One attentional component, the central executive, is aided by two peripheral and independent systems - the phonological loop and the visuospatial sketchpad - that temporary store verbal, and visuospatial information. Evidence for the separability of the subsystems of working memory are now abundant. For instance, verbal concurrent tasks affect short-term storage of verbal information but not that of visuospatial information. Conversely, maintenance of visuo-spatial information is disrupted by concurrent visuospatial tasks but not by verbal secondary tasks (Cocchini, Logie, Della Sala, MacPherson \& Baddeley, 2002). Brain-imaging studies also indicates that different neural areas underlie verbal and visuospatial short-term storage (Smith \& Jonides, 1997). Finally, studies of brain-damaged patients and of genetic disorders report selective loss of either verbal or visuospatial short-term memory (Jarrold, Baddeley \& Hewes, 1999).

The phonological loop is specialized for the short-term storage and processing of verbal and acoustic information. It is fractionated into a passive and temporary phonological store and an active rehearsal system. Because the information stored in the phonological store decays with time, the rehearsal system can refresh this information. This fractionation of the phonological loop is supported by neuropsychological findings and by neuroimaging data (Baddeley, 2000). The phonological loop gives account of several phenomena, such as the articulatory suppression and the phonological similarity effects. By contrast, the sketchpad is assumed to hold visuospatial information. Although the theoretical development of this system lags behind that of the phonological loop, and that there is less consensus about its functions, it is generally accepted that the sketchpad can be fractionated into two visual and spatial components (Logie, 1995). The visual component (the visual cache) is a passive system that stores visual information and spatial locations in the form of static visual representation. The spatial component (the inner scribe) is an active spatial rehearsal system that maintains sequential locations and movements and that also serves to refresh decaying information in the visual cache. Smith and Jonides (1997) provided findings supporting the fractionation of the sketchpad. In a PET study, they shown that different neural circuits and distinct cortical regions mediate the spatial and visual working memory systems.

Compared with the phonological loop and the visuospatial sketchpad, the central executive has long been the less specified system of working memory. Baddeley (1986) first borrowed the SAS model of attentional control developed by Norman and Shallice (1986) to explain how cognitive activities are managed. The conceptualization of the central executive then evolved (Baddeley, 1996) to a more specified system performing functions such as retrieval from long-term memory, selective and divided attention, switching attention, task switching, coordination of the slave-systems. As such, the central executive is now conceived as a system regulating and controlling information in working memory. Whatever its conceptualization, the central executive has been recognized as playing a crucial role in complex cognitive activities and being in the heart of the control of action. Finally, whether or not the different functions assigned to the central executive are separated is still discussed (Baddeley, 2001).

Competing models of working memory have been proposed (for a presentation of these models, see Myake \& Shah, 1999). For example, Cowan (2001) regards working memory as an activated portion of long-term memory and Just \& Carpenter (1992) conceived working memory as a single and limited pool of cognitive resources in which all processes draw and are in competition for sharing that resources. Although at a rapid glance these different approaches of working memory seem antagonistic, they can be considered complementary. Indeed, following Baddeley (1996) these competing theories of working memory might simply reflect the functions of the central executive and, therefore, can be reconciled with its multi-component model of working memory. Furthermore, according to Baddeley and Hitch (2001, p. xvii) there is "a general acceptance of the need to assume both of a general executive system and specific verbal and visual systems."

\section{Working Memory in Writing}

A large number of studies investigated the role of working memory in verbal activities (e.g., Caplan \& Waters, 1999; Gathercole \& Baddeley, 1993; Just \& Carpenter, 1992). Most of these studies explored the impact of individual differences on verbal performance as, for example, in text comprehension studies. In writing, the impact of individual differences in working memory on writing performance was mainly investigated by Swanson and Berninger and their collaborators who adopted a correlational approach for investigating the development of writing skill (for reviews, see Berninger \& Swanson, 1994; Swanson \& Berninger, 1996). By contrast, the precise relationship between working memory and the writing processes has been investigated only recently. This can 
appear surprising given the complexity of writing. However, this can be understood by looking to the theoretical frameworks of writing that were proposed in the literature: the implication of working memory in writing was not sufficiently portrayed and was still unspecified until 1996 where two majors contributions on the role of working in writing were published (Kellogg, 1996; McCutchen, 1996).

McCutchen (1996) adapted Just \& Carpenter's (1992) capacity theory of comprehension to account for developmental and individual differences in writing skill. Accordingly, the more efficient the writing processes, the less they require resources from working memory and the more resources are available for activating other processes and for coordinating goals. She surveyed studies bringing to the front capacity accounts of writing. She reviewed correlational and experimental studies showing that a greater efficiency in the writing processes, in particular in terms of fluency of operations, results in a better management of working memory resources and beside, in a better writing performance. Surprisingly, among all the studies she reported, only a few used a dualtask paradigm (for example, Kellogg, 1987; see below).

The second influential contribution was the model of working memory in writing that was proposed by Kellogg (1996) that adopted Baddeley's multi-component model of working memory. Kellogg (1996) justified this choice arguing that Baddeley's model has already been extended to work on language production and comprehension (Gathercole \& Baddeley, 1993).Further, Baddeley's model of working memory has been influential in cognitive, developmental and comparative psychology, as well as in neuroscience. It stimulated and still stimulates a extremely large number of studies and it accounts for a wide range of data (Andrade, 2001; Baddeley, 2001).

In his model, Kellogg analyzed how the working memory systems support writing and he clearly delineated the relationship between each writing process and the phonological loop, visuospatial sketchpad and central executive. Like McCutchen (1996), Kellogg first pointed out the capacity limitation of working memory and the fact that all writing processes place heavy demands on the central executive (considered as a pool of cognitive resources). Second, it analyzed how code-specific components of working memory (the phonological loop and the visuospatial sketchpad) are differently engaged by the writing processes. Accordingly, because in planning writers visualize images, organize diagrams and plans, planning processes require access mainly to the visuospatial sketchpad. By contrast, both translating, reading and surely editing impose large demands on the phonological loop (for a review, see Alamargot \& Chanquoy, 2001, chapter 5). Finally, the execution component engages none of the slave systems. By contrast with McCutchen proposals that focused on individual differences and development of writing, Kellogg's model aimed at describing the demands of writing on working memory in adult and expert writing. This model appeared heuristic and many experiments, whose majority used the dual-task paradigm, have now been conducted to test its assumptions.

In this framework, how working memory intervenes in writing can be studied according to two points of view. Firstly, it may consist in investigating the demands of writing in short-term storage, namely the relationship between the writing processes and the slave systems. Secondly, because of the large number of processes required to compose a text and the limited capacity of working memory, the role of working memory in written production can be investigated by studying the attentional and management functions of the central executive.

\section{Some findings on verbal and visuospatial short-term working memory in writing}

Kellogg (1996) has argued that spatial working memory supports planning conceptual content and that verbal working memory supports translation of this content into sentences. Kellogg, Olive and Piolat (in press) tested this assumption in a sentence generation task. Participants wrote definitions of either abstract or councrete nouns while concurrently performing a secondary task that required the detection of visually presented targets that were either verbal (ba or da) or visual (a triangle or a circle). Participants had to detect whether the target was different from the last one presented. Sentence length, secondary task accuracy and secondary reaction times were collected and were disrupted by the verbal and visual secondary tasks. More precisely, the verbal task disrupted the production of definitions of both the concrete and abstract nouns whereas the visual task disrupted the production of definitions of only the concrete nouns. This findings is consistent with Kellogg's (1996) claims that verbal working memory is needed for the linguistic encoding of sentences and that visual working memory is needed for planning image-based conceptual content.

The role of the visuospatial sketchpad in writing has been mainly conducted with tasks asking subjects to memorize a spatial or visual material (Levy \& Ransdell, 2001). For example, arguing that the composition of a descriptive text implies more mental imagery than that of argumentative text, Passerault and Dinet (2001) hypothesized that overloading the visuospatial sketchpad should have more impact with descriptive texts than with argumentative texts. As expected, writers' fluency was more slowed down when composing descriptive texts. 
By contrast, studies of the phonological loop generally do not involve any memorization. The goal of such phonological secondary tasks used is to interfere with either the processing, the temporary storage or the refreshment of information in the phonological loop. For example, in the unattended speech task, while they compose a text, participants hear a speech to which they do not have to pay attention. In the articulatory suppression task, participants continually repeat unmeaning syllables. Madigan, Johnson and Linton (1994) observed that an unattended speech task affected writer's fluency but had no effect on the quality of the texts. Exploring further why an unattended speech affects writing, Marek and Levy (1999) observed any differences between an unattended speech task made by a coherent text or an incoherent one. They thus demonstrated that the effect of this unattended speech is mainly related to a phonological interference rather than to its semantic integration. Marek and Levy (1999) extended their findings by exploring the relation of the phonological loop with each writing process. They used three different writing tasks, each one being designed to engage mainly one particular writing process. In the first task where participants had to generate a sentence from several words, formulation processes were assumed to be mainly engaged. In the second task, only execution processes where supposed to be involved because participants copied a text. Finally in the third task, editing a text, revision processes were mainly engaged. Simultaneously to these three tasks, participants were submitted to a secondary task of unattended speech. According to Kellogg (1996), because only formulation would engage the phonological loop, the unattended speech task should have no effect on the copying and revision tasks. The speed and errors of typing during the copying task were not affected by the unattended speech. In the revision task, the unattended speech had no effect on the number of errors detected. By contrast, in the sentence generation task writer's forgot to included source words and subjective quality of the sentences was judged lower when it was performed with an unattended speech than without an unattended speech. These data lead Marek and Levy (1999) to conclude that the formulation processes need stronger access to the phonological loop than the execution and revision processes did.

In another experiment, Levy and its collaborators (see Levy \& Ransdell, 2001) instructed their participants to perform secondary tasks that aimed at overloading each sub-system of working memory (i.e., the phonological loop, the central executive and the visuospatial sketchpad). All secondary stimuli were characters. The single characteristic that allowed differentiating these secondary tasks was the dimension of the characters that participants had to process to make a response. Indeed, about all two seconds, the character, its color, its font or its location changed. Thus, in the phonological condition, writers had to reply when two consecutive characters shared the same phoneme (for instance [i], e.g., in English: b, c, d). In the visuospatial task, writers had to detect when two consecutive characters were at the same place, or were similar in color. In the task aiming at overloading the central executive, writers had to reply when two consecutive characters formed a two-letter English word. Consistent with Kellogg's model (1996), the visuospatial task produced the strongest decrease of the initial planning time (pre-handwriting pause). However, contrarily to Kellogg's propositions, the phonological task produced a larger effect on this initial planning time than when the central executive was required. This result therefore demonstrates that the phonological loop is also engaged during planning.

These different experiments highlights the role of the phonological loop and the visuospatial sketchpad in writing. Even if the majority of studies that have been conducted lead to findings generally consistent with the initial proposals of Kellogg about the relationship between the sub-systems of working memory and the writing processes, some evidences stem the predictions of the model. In particular, the question of the relationships between the phonological loop and the planning process still remains. Finally, with respect to the dual-task issue, it is important to notice that in the different dual-task experiments presented above, the "unintrusiveness" criterion suggested by Fisk et al. (1986-87) cannot be respected. Indeed, in order to decide whether or not a component of working memory is required for performing the primary task, the effect of the secondary task can be assessed by comparing performance in single- versus dual-task condition but of either the primary task or the secondary task, or both. As it is shown in the next section, performance has to be analyzed differently when one focuses on attentional and executive functions of working memory.

\section{Some Findings on Attentional and Executive Functioning in Writing}

As indicated in the introduction of this paper, writing is a highly integrative activity. Furthermore, all writing processes, excepted graphic transcription in adults, place high demands on the central executive of working memory (Kellogg, 1996). Composing a text thus requires shifting between --and presumably concurrently activating-- several writing processes. Research on the role of the central executive in writing has therefore to 
analyze how the different writing processes are activated in the course of writing. In other words, it means exploring the strategies writers activate for managing the writing processes in the course of writing (Fayol, 1999). On another hand, it has to study how writers succeed (or not) in activating the different writing processes without exceeding the limits of working memory (for a review, see Brown \& Carr, 1989). This means also evaluating the amount of resources that is devoted to each of these processes.

\section{The Demands and Temporal Organization of the Writing Processes}

The triple task method (initially proposed by Kellogg, 1987) had proved fruitful for addressing these issues (for a review, see Olive, Kellogg \& Piolat, 2001). The general principle of the triple-task method requires participants to perform a primary task (in the present case the composition of a text), a probe task and to verbalize about the primary task. In practice, two variants of the triple task have been used. In the first variant, the verbalization is directed. After each reaction to a probe the writer categorizes his thought according to categories referring to the writing processes (Kellogg, 1987). In the second variant, participants think aloud throughout the primary task and the writing processes are identified by mean of a classical verbal protocol analysis (Levy \& Ransdell, 1995). Two variables are then analyzed. First, the verbalization data provide information about how the writing processes are activated. Second, the reaction times to the probes allows studying allocation of cognitive resources to these processes. Indeed, each reaction time (RT) to a probe is associated with a verbalization data and the latency of these RTs (in term of a difference with a baseline RT) can be interpreted as estimating the amount of cognitive resources (or processing demands) that is devoted to each writing process. Latency of secondary reaction times has indeed been considered reflecting allocation of cognitive resources in studies of mental chronometry.

The experiments that were carried out with the triple task thus analyzed processing demands and activation of the writing processes. They attempted to examine whether one process dominates the others at particular points in time and whether these relationship changes as writing progresses, in other words the goal was to determine the general functioning characteristics of writing. They also tried to assess the demands in central resources of each writing process. The impact of several factors on both the processing demands and activation of the writing processes was also examined to further understand how these general functioning characteristics interacted with writer's inter-individual differences (domain knowledge, verbal skill, working memory capacity,...) and with the composition situations (writing strategies, writing in first or second language, medium of production,...; for a review, see Olive, Kellogg \& Piolat, 2001, and Piolat \& Olive, 2000).

Regarding the general functioning characteristics of writing (i.e., the processing demands and the activation of the writing processes during a composition), the results do not always converge. This is due to the fact that both the processing demands and the activation of the writing processes vary with the specific demands of the task and the knowledge and skills of the writers. Nevertheless, without taking into account the factors that were manipulated, some stable findings can be drawn from these experiments. First, planning, but also revision with a less extent, place more demands on working memory than translating processes do. The lighter demands on working memory of translating can be explained by noting that translating sub-processes are also involved in the production of spoken language. Second, translating is the most often activated process but planning is more activated than revision, although the reverse is observed in a few studies for these two last processes (more detailed information can be found in Olive, Kellogg \& Piolat, 2001, and in Piolat \& Olive, 2000). Moreover, throughout a writing session, activation of translating remains constant while that of planning decreases and that of revision increases.

The previous findings show that the triple task has provided new data about invariant functional characteristics of writing. Some general features of the writing processes have been described. However, one important issue that has to be addressed in writing research concerns the way writers adapt their writing strategies to different situations of composition and whether their level of knowledge, their skills, their working memory capacity, and so on, affect these strategies (see Table 1). In this perspective, in their review, Olive Kellogg and Piolat (2001; Piolat \& Olive, 2000) have identified three groups of factors that seem to affect the writing processes in different ways. First, it appears that processing demands of the writing processes are mainly affected by writers individual differences. In particular, a high availability of knowledge of the writer about the topic of the text induces a lower cognitive effort (see also Kellogg, 2001). Second, activation of the writing processes, and especially that of planning and of revision, is influenced by situation-specific factors. In other words, the temporal organization of these processes is principally affected by the way writers organize their composition. Finally, writer's linguistic skill and medium of production have repercussions on both the activation of the writing processes and on their processing demands.

The dynamic of writing, how the writing processes are activated was also explored by Levy and Ransdell 
(1995) who studied how writers shift between the various writing processes, in other words, the recursivity of writing. They calculated the frequencies of transition between the different writing processes (i.e., the frequency of all the possible and actual shifts between processes).

They shown that each writer preferably alternates between some specific writing processes, and that these individual patterns of transition between the writing processes are stable in different phases of a writing session. Moreover, because their participants composed different texts during different writing sessions, they were able to study whether a same writer applies several writing strategies. Surprisingly, they observed that each writer uses the same strategy in all the different writing sessions. The great intra-individual stability of these patterns and the inter-individual differences in terms of processes transitions lead them to call these writers-specific strategies of management of writing the "writing signatures".

With their method, they were thus able to elicit individual differences in terms of management of the dynamic of writing. Unfortunately, how these 'writing signatures' are affected by writers- and situation-specific factors has still not been addressed.

\section{Table 1}

Summary of effects of writers- and situation-specific factors on processing demands and activation of the writing processes.

\begin{tabular}{|lcc|}
\hline & $\begin{array}{c}\text { Processing } \\
\text { demands }\end{array}$ & Activation \\
\hline Topic knowledge & Yes & No \\
Kellogg (1987) & Interaction with verbal skill \\
\hline Olive, Piolat \& Roussey (1997) & No & No \\
\hline Kerbal skill & Interaction with topic \\
Olive, Piolat \& Roussey (1997) & & \\
knowledge & & \\
\hline Writing strategy & & Yes \\
Kellogg (1987, 1988) & $\ldots$ & Yes \\
Type of draft & Yes & \\
Type of plan & & Yes \\
\hline Medium of production & Yes & Yes \\
Kellogg (2001) & Yes & Yes \\
Kellogg \& Mueller (1993) & No & No \\
Olive, Piolat \& Polge (1997) & & No \\
\hline Type of text & No & Yes \\
Kellogg (2001) & No & \\
\hline WM capacity & & \\
Piolat \& Fruttero (1998) & & \\
Penningroth \& Rosenberg (1995) & & \\
\hline Addressee & & \\
Piolat, Roussey \& Roux (1996) & & \\
\hline
\end{tabular}

All the works cited above allowed characterizing the dynamic of the writing processes as well as their processing demands. Their findings allow two general observations. On one hand, a certain stability in the general pattern of activation of the writing processes and in their processing demands appears. However, these general functioning characteristics are affected both by inter-individual differences and by situation-specific factors. On another hand, individual differences in the writing strategies (i.e., the way the writing processes are activated) are well described in terms of transitions between the writing processes (such the 'writing signatures' of Levy \& Ransdell, 1995). So far, not enough studies have been conducted to reach firm conclusions about the effects of individual differences on the dynamic of writing. Future researches should more systematically explore the effects of individual differences both on the dynamic of writing and on writing performance.

\section{Concurrent Activation of the Writing Processes}

The experiments described above on the composing strategies of writers only deal with sequences of writing processes, as if they were activated only sequentially. However, to the extent that sufficient resources are available, writers can activate several processes in parallel (Kellogg, 1996). A very few studies addressed this issue. In this section, I will report results of a dual-task experiment that investigated how the central executive coordinates the transcription process and planning, translating and reviewing during writing (Olive \& Kellogg, 2002).

In this study, as a primary task, we asked our participants to compose a text and copy it using a digitizer tablet. It was thus possible to identify when they were actually handwriting or pausing. The secondary task we used was a probe task. However, unlike the triple-task, writers did not perform any verbalization. The findings of this experiment revealed that in a composition task, when the probes occurred while adults writers transcribed their text, RT interference (or latency) was longer than when the probes occurred while writers were pausing. Moreover, RT interference was even more brief when writers were transcribing their text but during a copying task. These differences can be easily explained if one considers that adult writers, at the same time that they write, simultaneously activate the high level writing processes (planning, translating and reviewing). By contrast, during 
pauses only these high level processes are activated and during handwriting in the copying task only transcription processes are activated. Furthermore, we have shown that this concurrent activation of the low and high level writing processes mainly resulted from the automatization of the transcription processes. For instance, in third graders children, RT interference associated to transcription was higher than in adults but no longer differed in the copying and composing tasks in children. This finding corroborates the idea that the increase of resources required by transcription processes no longer allows children activating the high level writing processes at the same time they write down their text. We provided further evidence consistent with this interpretation showing that adults composing with an unfamiliar calligraphy (with upper-case cursive handwriting) also activated the low and high level writing processes step-by-step (see also Olive \& Piolat, 2002 for the same results with a suppression of visual feedback). These results point out the adaptive management of writing. Some authors (Fayol, 1999; Levy \& Ransdell, 1995) have besides suggested that writers' level of expertise may partially be linked to this ability in adapting the dynamics of activation of the writing processes to the changing demands of writing.

\section{Conclusion}

As shown in this short review, the dual-task technique largely contributed in showing how the limits of working memory force the composition of a text. This technique allows highlighting the relationship between each component of working memory and the various writing processes. They also allows researcher investigating how writers strategically control the course of writing for adapting to its changes in cognitive demands.

The dual-task technique has raised very important discussion in cognitive psychology. It is clear that psychologists must be attentive when selecting a secondary task and proposals like those of Fisk, Derrick and Schneider (1986-87) contributed in such selection. It must be noted, however, that some of the criteria of Fisk, Derrick and Schneider are not always relevant. For example, with concurrent memory load tasks, performance of either the primary task or the secondary or both can be affected. Moreover, their criterion about the community of resources has no more relevance with multi-components models of working memory such as Baddeley's one (1986).

In spite of this, the present article has shown that several variants of the dual-task technique can be fruitfully implemented but that the choice of a particular secondary task is crucial because it depends on how it is expected to interact with the primary task. For instance, when aimed at studying relationships between a cognitive process or activity and a working memory component, the decrease of performance resulting from the secondary task can be observed on either the primary or the secondary tasks, or both. By contrast, when one attempts to evaluate central demands of the primary task in usual conditions of realization, performance of only the secondary task must decrease (the amplitude of its decrease indicating the amount of resources that was required by the primary task). Finally, the use of the dual-task technique can aim at inducing modifications of performance of the primary task. Studies on subject-verb agreement processes conducted by Fayol and its collaborators (see Fayol, 1997) illustrate well this point. These authors used different secondary tasks according to the predictions they tested but also according to the age of writers. For instance, in order adults create spelling errors that they usually do not make, Fayol et al. used large concurrent memory loads. By contrast, in order to show that the processes underlying subject-verb agreement gradually automatize with development, children of different ages were submitted to a probe task.

Finally, although this article has exclusively brought data stemming from dual-task experiments, other techniques are available for studying the on-line management of writing. For example, analysis of verbal fluency (or dysfluency) also contributed to the understanding of writers' management strategies. Frequency or duration of pauses, and variations of fluency are indeed reliable indicators of strategic changes of management of processes (Fayol, 1999). Furthermore, analyses of ocular movements of writers should bring crucial information on the time course of cognitive processes engaged in text composition.

\section{References}

Alamargot, D. \& Chanquoy, L. (2001). Though the models of writing. Dordrecht: Kluwer Academic Publishers.

Andrade, J. (Ed.) (2001). Working memory in perspective. Hove: Psychology Press.

Atkinson, R. C. \& Shiffrin, R. M. (1968). Human memory. In K. W. Spence (Ed.), The psychology of learning and motivation: Advances in research and theory (pp. 89-195). New York: Academic Press.

Baddeley, A. D. (1986). Working memory. New York: Oxford University Press. 
Baddeley, A. D. (1996). Exploring the central executive. The quarterly Journal of Experimental psychology, 49A (1), 5-28.

Baddeley, A. (2000). The episodic buffer: a new component of working memory? Trends in Cognitive Sciences, 4, 417-423.

Baddeley A. D. (2001). Is working memory still working? American Psychologist, 56, 849-864.

Baddeley, A. D. \& Hitch, G. (1974). Working memory. In G. H. Bower (Ed.), The psychology of learning and motivation (pp. $47-$ 90). New York: Academic Press.

Baddeley, A. D. \& Hitch, G. (2001). Working memory in perspective: Foreword. In J. Andrade (Ed.), Working memory in perspective (pp. xv-xix). Hove: Psychology Press.

Berninger, V. W. \& Swanson, H. L. (1994). Modifying Hayes and Flower's model of skilled writing to explain beginning and developing writing. In E. C. Butterfield (vol. Ed.), Advances in cognition and educational practice, Vol. 2. Children's writing: Toward a process theory of the development of skilled writing (pp. 57-81). Greenwich, CT: JAI Press.

Bock, J. K. \& Levelt, W. (1994). Language production: Grammatical encoding. In M. A. Gernsbacher (Ed.) Handbook of Psycholinguistics (pp. 945-984). San Diego: Academic Press.

Brown, T. L. \& Carr, T. H. (1989). Automaticity in skill acquisition: mecanisms for reducing interference in concurrent performance. Journal of Experimental Psychology: Human Perception \& Performance, 14, 45-59.

Caplan, D. \& Waters, G. S. (1999). Verbal working memory and sentence comprehension. Behavioral \& Brain Sciences, $22,77-$ 126.

Cocchini, G., Logie, R. H., Della Sara, S., MacPherson, S. e., \& Baddeley, A. D. (2002). Concurrent performance of two memory tasks: evidence for domain specific working memory systems. Memory \& Cognition, 30, 1086-1095.

Cowan, N. (2001). The magical number 4 in short-term memory: a reconsideration of mental storage. Behavioral and Brain Sciences, 24 (1), 87-185.

Fayol, M. (1997). Des idées an texte. Psychologie cognitive de la production verbale, orale et écrite. Paris : PUF.

Fayol, M. (1999). From on-line management problems to strategies in written production. In M. Torrance \& G. Jeffery (Eds), Cognitive demands of writing. Processing capacity and working memory effects in text production (pp. 13-24). Amsterdam: Amsterdam University Press.

Fisk, A. D., Derrick, W. L. \& Schneider, W. (1986-87). A methodological assessment and evaluation of dual-task paradigms. Current Psychological Research \& Reviews, 5, 315-327.

Gathercole, S. E. \& Baddeley, A. (1993). Working memory and language. Hillsdale, NJ: Lawrence Erlbaum Associates.

Hayes, J. R. \& Gradwohl Nash, J. (1996). On the nature of planning in writing. In C. M. Levy \& S. E. Ransdell (Eds.). The science of writing: Theories, methods, individual differences and applications (pp. 29-55). Mahwah, NJ: Lawrence Erlbaum.

Howe, M. L. \& Rabinowitz, F. M. (1989). On the uninterpretability of Dual-task performance. Journal of Experimental Child Psychology, 47, 32-38.

Humphrey, D. G., \& Kramer, A. F. (1994). Toward a psychophysiological assessment of dynamic changes in mental workload. Human Factors, 36, 3-26.

Jarrold, C., Baddeley, A. D., \& Hewes, A. K. (1999). Genetically dissociated components of working memory: evidence from Down's and Williams syndrome. Neuropsychologia, 37, 637-651.

Just, M. A. \& Carpenter, P. A. (1992). A capacity theory of comprehension: Individual differences in working memory. Psychological Review, 99, 122-149.

Kahneman, D. (1973). Attention and effort. Englewood Cliffs, NJ: Prentice-Hall.

Kellogg, R. T. (1987). Effects of topic knowledge on the allocation of processing time and cognitive effort to writing processes. Memory \& Cognition, 15, 256-266.

Kellogg, R. T. (1988). Attentional overload and writing performance: Effects of rough draft and outline strategies. Journal of Experimental Psychology: Learning, Memory, \& Cognition, 14, 355-365.

Kellogg, R. T. (1993). Observations on the psychology and thinking of writing. Composition studies, 21, 3-41.

Kellogg, R. T. (1996). A model of working memory in writing. In C. M. Levy \& S. E. Ransdell (Eds), The science of writing (pp. 57-71). Mahwah, NJ: Lawrence Erlbaum Associates.

Kellogg, R. T. (2001). Long-term working memory in text production. Memory \& Cognition, 29 (1), 43-52.

Kellogg, R. T. (2001). Competition for working memory among writing processes. American Journal of Psychology, 114 (2), $175-$ 192.

Kellogg, R. T., Olive, T., \& Piolat, A. (in press). Verbal and visual working memory in written sentence production. In D. Galbraith \& M. Torrance (Eds.), Basic processes in writing. Dordrecht: Kluwer Academic Publishers.

Kellogg, R. T. \& Mueller, S. (1993). Performance amplification and process restructuring in computer-based writing. Journal of Man-Machine Studies, 39, 33-49.

Kerr, B. (1973). Processing demands during mental operations. Memory and Cognition, 1, 401-412.

Levy, C. M. \& Ransdell, S. E. (1995). Is writing as difficult as it seems ? Memory and Cognition, 23 (6), 767-779.

Levy, C. M. \& Ransdell, S. (2001). Writing with concurrent memory loads. In T. Olive \& C. M. Levy (Eds), Contemporary tools and techniques for studying writing (pp. 9-30). Dordrecht: Kluwer Academic Publishers.

Logie, R. H. (1995). Visuospatial working memory. Hove, U.K.: Lawrence Erlbaum Associates.

Madigan, R. J., Johnson, S. E. \& Linton, P. W. (1994). Working memory capacity and the writing process. Paper presented at the 
American Psychological Society, Washington. DC.

Marek, J.P. \& Levy, C. M., (1999). Testing the role of the phonologocal loop in writing. In M. Torrance \& G. Jeffery (Eds.), Cognitive demands of writing. Amsterdam: Amsterdam University Press.

McCutchen, D. (1996). A capacity theory of writing: working memory in text composition. Educational Psychology Review, 8, 299-235.

Myake, A. \& Shah, P. (Eds.) (1999). Models of Working Memory: Mechanisms of Active Maintenance and Executive Control. Cambridge: Cambridge University Press.

Norman, D.A. \& Shallice, T. (1986). Attention to action : wiled and automatic control of behavior. In R.J. Davidson, G.E. Schwarts, \& D. Shapiro (Eds.), Consciousness and self-regulation. Advances in research and theory, vol. 4, (pp. 1-18). New York: Plenum Press.

Olive, T. \& Kellogg, R. T. (2002). Concurrent activation of high- and low-level production processes in written composition. Memory \& Cognition, 30 (4), 594-600.

Olive, T., Kellogg R. T., \& Piolat, A. (2001). The triple-task technique for studying the process of writing. In T. Olive \& C. M. Levy (Eds), Contemporary tools and techniques for studying writing (pp. 31-58). Dordrecht: Kluwer Academic Publishers.

Olive, T. \& Piolat, A. (2002). Suppressing visual feedback in written composition: Effects on processing demands and coordination of the writing processes. International Journal of Psychology, 37 (4), 209-218.

Olive, T., Piolat, A., \& Polge, M. (1997, August). An evaluation of mental effort of professional and experienced writers during the use of a word processor. Paper presented at the 7 th European Conference for Research on Learning and Instruction. Athens, Greece.

Olive, T., Piolat, A., \& Roussey J.-Y. (1997a). Effort cognitif et mobilisation des processus en production de texte : Effet de l'habileté rédactionnelle et du niveau de connaissances. In D. Mellier \& A. Vam Hoffe (Eds). Attention et contrôle cognitif: Mécanismes, développement des habiletés, pathologies (pp. 71-85). Rouen: Publications de l'Université de Rouen.

Passerault, J.-M. \& Dinet, J. (2000). The role of visuospatial sketchpad in the written production of descriptive and argumentative texts. Current Psychology Letters: Behavior, Brain \& Cognition, 3, 31-42.

Penningroth, S.L. \& Rosenberg, S. (1995). Effects of a high information-processing load on the writing process and the story written. Applied Psycholinguistics, 16, 189-210.

Piolat, A. \& Fruttero, L. (1998). Effects of memory span on cognitive load and composing strategies related to writing processes. In E. Esperet \& M.-F. Crété (Eds.), Proceedings of the 1998 Writing Conference (pp. 385-390). Poitiers: MSHS, Université de Poitiers.

Piolat, A. \& Olive, T. (2000). Comment étudier le coût et le déroulement de la rédaction de textes ? La méthode de tripletâche : un bilan méthodologique. L'Année Psychologique, 100, 465-502.

Piolat, A., Olive, T., Roussey, J.-Y., Thunin, O. \& Ziegler, J. C. (1999). Scriptkell : a computer assisted tool for measuring the relative distribution of time and cogntive effort in writing and other tasks. Behavior Research Methods, Instruments, \& Computers, 31 (1), 113-121.

Piolat, A., Roussey, J.-Y., \& Rous, P. (October, 1996). Effects of attention directed to different texts on the mental effort related to writing processes. Graphic presentation at the 1996 European Writing Conferences, Barcelone, Spain.

Posner, M. I. (1978). Chronometric explorations of mind. Hillsdale, NJ: Lawrence Erlbaum.

Power, M. J. (1986). A technique for measuring processing load during speech production. Journal of Psycholinguistic Research, 15, 367-385.

Schneider, W. \& Shiffrin, R. M. (1977). Controlled and automatic human information processing: I. Detection, search, and attention. Psychological Review, 84 (1), 1-66.

Smith, E. E. \& Jonides, J. (1997). Working memory: a view from neuroimaging. Cognitive Psychology, 33, 5-42.

Swanson, H. L. \& Berninger, V. W. (1996). Individual differences in children's working memory and writing skill. Journal of experimental Psychology, 63 (2), 358-385. 